\title{
Cloud Geospasial Self-Managed Services untuk Katalog Data Seismik dan Nonseismik Migas PT Pertamina Hulu Energi
}

\author{
Geospatial Cloud Self-Managed Services for Seismic and Non-seismic Data Catalog of Oil and Gas PT Pertamina \\ Hulu Energi
}

\author{
Rifqi Rabbani Kusumah*1, Teguh Hariyanto², Akbar Kurniawan ${ }^{3}$ \\ ${ }^{1,2,3}$ Departemen Teknik Geomatika, FTSLK-ITS, Kampus ITS Sukolilo, Surabaya, 60111, Indonesia \\ *Korespondensi penulis: rifqirabbani.k@gmail.com
}

Diterima: 14082020; Diperbaiki: 15092020; Disetujui: 22092020; Dipublikasi: 21012021

\begin{abstract}
Abstrak: PT Pertamina Hulu Energi (PHE) sebagai perusahaan holding yang mempunyai 52 Anak Perusahaan Hulu memerlukan teknologi terkini dalam melakukan manajemen data. Salah satu manajemen data yang dilakukan untuk kegiatan evaluasi pematangan propsek migas berupa data seismik dan nonseismik. Permasalahan yang terjadi adalah data-data tersebut masih berupa laporan kertas dan spreadsheet yang kompleks. Kondisi tersebut akan menyulitkan analyst di PT Pertamina Hulu Energi untuk mengintegrasikan dan meninjau kembali data-data tersebut. Oleh karena itu pada penelitian ini akan memanfaatkan cloud geospasial self-managed services untuk katalog data seismik dan nonseismik. Pengumpulan data seismik dan nonseismik akan disesuaikan sesuai standar yang ada. Kemudian katalog data seismik dan nonseismik masuk ke perangkat lunak sistem informasi geografis untuk dilakukan publish data ke cloud geospasial yang bersifat online. Dari sistem online tersebut akan dikembangkan aplikasi untuk menunjang manajemen katalog data seismik dan nonseismik berupa web app, operations dashboard, dan story maps. Web app berguna untuk menampilkan web map, dan melakukan query. Operations Dashboard berguna untuk menampilkan infografik progress pengisian data. Story maps berguna untuk melihat ringkasan singkat hasil studi nonseismik. Dalam penerapannya sistem cloud geospasial akan berfungsi sebagai storage pengumpulan data yang bisa dilakukan update secara berkala dan hanya dapat diakses oleh PT Pertamina Hulu Energi.
\end{abstract}

Copyright $@ 2020$ Geoid. All rights reserved.

\begin{abstract}
PT Pertamina Hulu Energi (PHE) as a holding company that has 52 upstream subsidiaries requires the latest technology in data management. One of the data management carried out to evaluate oil and gas prospects is in the form of seismic and nonseismic data. The problem is that the data is still in the form of paper-based reports and complex spreadsheets. This condition will make it difficult for analysts at PHE to integrate and review these data. Therefore, this research will utilize geospatial cloud self-managed services for seismic and nonseismic data catalogs. Seismic and nonseismic data collection will be adjusted according to standards. Then the seismic and nonseismic data catalogs enter the geographic information system software to publish data to the online geospatial cloud. From this online system, an application will be developed to support management of seismic and nonseismic data catalogs likes a web app, operations dashboard, and story maps. Web app is useful for displaying web maps, widgets, and performing queries. Operations Dashboard is useful for displaying infographics of data entry progress. Story maps are useful for viewing a brief summary of the results of a nonseismic study. In its application, the geospatial cloud system will function as data collection storage that can be updated regularly and can only be accessed by PHE.
\end{abstract}

Kata kunci: Kesesuaian lahan; Penginderaan jauh; SIG

\section{Pendahuluan}

PT Pertamina Hulu Energi sebagai perusahaan di bidang sektor migas memiliki kegiatan usaha di 52 anak perusahaan hulu (APH) yang tersebar di Indonesia. Kegiatan usaha yang sudah dilakukan meliputi eksplorasi diantaranya adalah survei seismik baik seismik 2D maupun 3D. Selain survei seismik, survei nonseismik juga sudah dilakukan perusahaan tersebut. Kegiatan survei seismik dan nonseismik geofisika dilakukan untuk mengetahui kondisi di bawah permukaan bumi melibatkan pengukuran di atas permukaan bumi dari parameter-parameter fisika yang dimiliki oleh batuan di dalam bumi (Sheriff, 1991). Survei seismik dan 
nonseismik yang dilakukan bertujuan untuk evaluasi pematangan prospek migas di lapangan produksi PT Pertamina Hulu Energi.

Data hasil survei yang sudah dilakukan masih berupa laporan-laporan kertas dan data spreadsheet yang kompleks. Selain itu, data-data tersebut masih tersebar di setiap anak perusahaan hulu (APH) PT Pertamina Hulu Energi. Kondisi tersebut akan menyulitkan para analyst di perusahaan tersebut untuk mengintegrasikan dan meninjau kembali informasi dari hasil survei tersebut. Maka dari itu diperlukan pengelolaan data survei seismik dan nonseismik berbasis sistem informasi geografis (SIG) karena sistem informasi geografis memiliki kemampuan dalam membuat kombinasi data spasial dari berbagai sumber untuk menghasilkan informasi yang dibutuhkan dalam pengambilan keputusan (Anam, 2012).

Konsep sistem informasi geografis untuk menunjang manajemen data, proses dimulai dari input data, pengolahan, dan representasi dalam bentuk peta input data, manajemen, analisis, dan representasi data (Charter, 2004). Data seismik dan data nonseismik diintegrasikan sesuai dengan standar untuk memudahkan pencarian data sesuai kebutuhan perusahaan dan tidak terjadi duplikasi. Data-data yang diintegrasikan pada survei seismik dan nonseismik tersebut merupakan data spasial dan nonspasial yang penting digunakan dalam mendukung kegiatan eksplorasi sebagai salah satu tahapan dalam life cycle industri hulu migas (IOGP, 2019).

Data-data yang sudah dibuatkan katalog di dalam sistem informasi geografis akan dilakukan publish ke dalam cloud geospasial jenis self-managed services menggunakan ArcGIS Enterprise agar data bersifat online. ArcGIS Enterprise menerapkan enterprise geodatabase yang memiliki karakteristik mempermudah pemasukkan, pengolahan, dan penampilan data pada tingkat perusahaan atau organisasi karena dibangun dengan manajemen basis data relasional yang baik seperti SQLServer, Oracle, dll (ESRI, 2017). Data-data yang sudah terpublish akan ditampilkan melalui GIS portal berupa web map. Untuk menunjang manajemen data, selanjutnya data-data di dalam cloud geospasial dikembangkan menjadi tiga aplikasi yaitu web app, operations dashboard, dan story maps yang nantinya bisa dilakukan update secara berkala dan hanya dapat diakses PT Pertamina Hulu Energi.

\section{Data dan Metode}

Penelitian ini dilakukan pada studi kasus di wilayah kerja X PHE sebagai studi kasus data seismik terletak di Provinsi Sumatra Selatan dengan koordinat $1^{\circ} 20^{\prime} 00^{\prime \prime}$ LS - $5^{\circ} 10^{\prime} 00^{\prime \prime}$ LS dan $101^{\circ} 40^{\prime} 00^{\prime \prime}$ BT - 106 $30^{\prime} 00^{\prime \prime}$ BT dan Provinsi Jambi dengan koordinat $0^{\circ} 45^{\prime} 00^{\prime \prime}$ LS - $2^{\circ} 45^{\prime} 00^{\prime \prime}$ LS dan $101^{\circ} 10^{\prime} 00^{\prime \prime}$ BT - 104 55'00" BT. Pemilihan lokasi pada wilayah kerja X PHE dikarenakan prospek migas di wilayah tersebut sangat baik dan data yang tersedia bisa dikembangkan untuk manajemen data seismik.

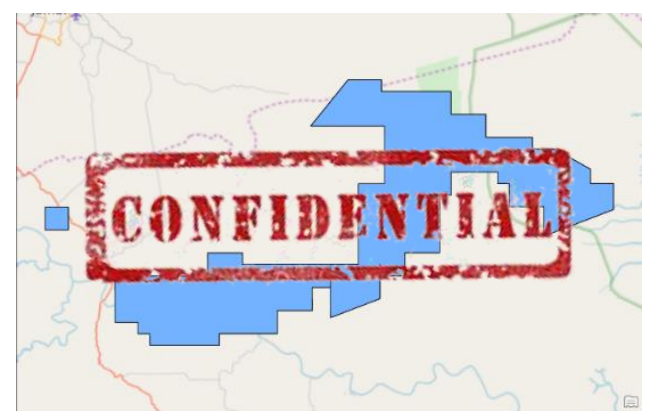

Gambar 1. Wilayah Kerja X PHE

Selanjutnya wilayah kerja Y PHE sebagai studi kasus data nonseismik terletak di Provinsi Jawa Timur dengan koordinat $7^{\circ} 12^{\prime} 00^{\prime \prime} \mathrm{LS}-8^{\circ} 00^{\prime} 48^{\prime \prime} \mathrm{LS}$ dan $111^{\circ} 00^{\prime} 00^{\prime \prime} \mathrm{BT}-114^{\circ} 04^{\prime} 00^{\prime}$ ' BT. Pemilihan lokasi pada wilayah kerja Y PHE dikarenakan dalam beberapa waktu terakhir baru saja dilakukan akuisisi survei nonseismik sehingga bisa dikembangkan untuk manajemen data nonseismik. 


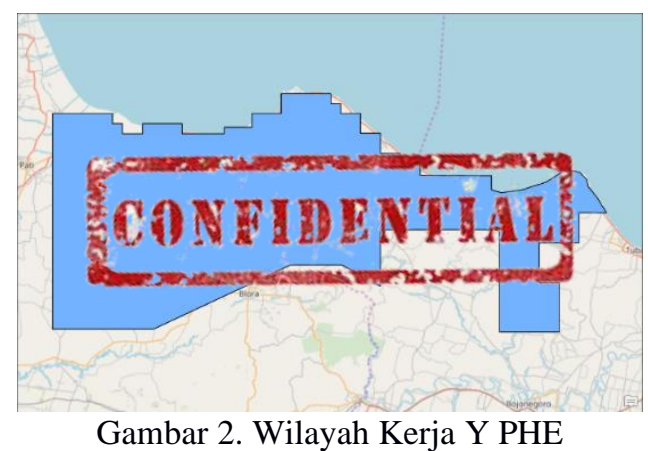

Data yang digunakan dalam penelitian ini yaitu: data spreadsheet navigasi akuisisi survei seismik 2D wilayah kerja X Tahun 1990 s.d. 2012; data spreadsheet nonseismik yaitu gravity dan CSAMT (controlled source audio-frequency magnetotelluric) wilayah kerja Y blok timur Tahun 2019; data spasial penunjang seperti wells, well trajectory, prospect and lead, batas wilayah kerja, dan peta dasar geologi dalam format shapefile (*.shp); dan gambar penunjang seperti penampang seismik 2D dan penampang gravity dengan CSAMT dalam format Joint Photographic Experts Group (*.jpeg) atau format Portable Network Graphics (*.png). Untuk peralatan yang digunakan dalam penelitian ini yaitu: ArcGIS Desktop atau ArcGIS Pro untuk pengolahan data spasial dalam sistem informasi geografis; ArcGIS Enterprise PT Pertamina Hulu Energi sebagai cloud geospasial selfmanaged services; Microsoft Excel untuk kompilasi data pengolahan data spreadsheet; laptop; dan workstation (PC) yang terhubung server PT Pertamina Hulu Energi.

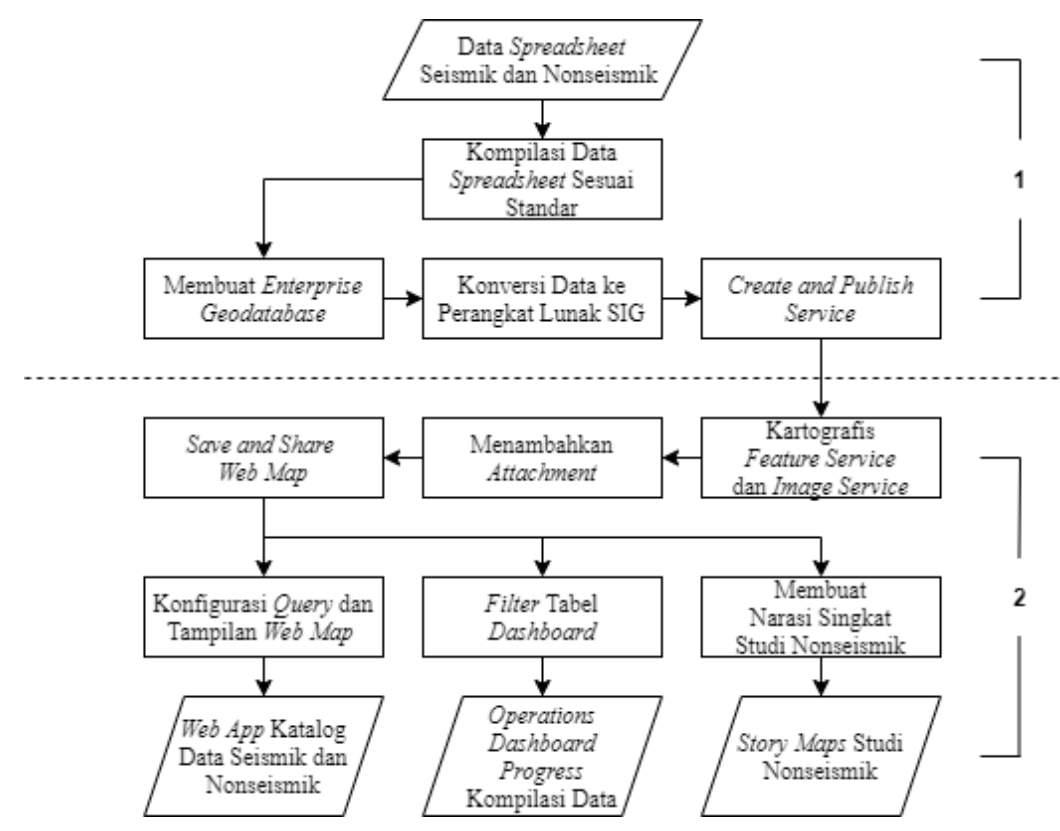

Gambar 3. Diagram Alir Pengolahan Data

Pada diagram alir di atas dapat dilihat pengolahan data terbagi menjadi dua lingkup. Untuk lingkup nomor 1 merupakan pengolahan data pada sistem informasi geografis. Data spreadsheet yang dikompilasi sesuai standar dikonversi menjadi sebuah katalog ke dalam enterprise geodatabase sistem informasi geografis sehingga nantinya bisa dilakukan publish ke dalam cloud geospasial self-managed services agar data bersifat online. Untuk lingkup nomor 2 merupakan pengolahan data pada cloud geospasial self-managed services. Data yang sudah terpublish dilakukan kartografis untuk mengatur kembali penamaan data spasial, tampilan pop up, label yang ingin ditampilkan, dan image display. Kemudian data ditambahkan attachment berupa informasi gambar penunjang sampai menjadi sebuah web map. Dari web map akan dikembangkan menjadi aplikasi web 
app katalog data seismik dan nonseismik, operations dashboard progress kompilasi data, dan story maps studi nonseismik.

\section{Hasil dan Pembahasan}

\section{Kompilasi Data Spreadsheet Sesuai Standar}

Data spreadsheet seismik dan nonseismik yang terpisah dikompilasi sesuai standar yang ada. Standar yang digunakan yaitu PPDM 3.9 untuk data seismik 2D dan Standar Metadata Katalog Pengadministrasian Data Minyak dan Gas Bumi dari Kementerian ESDM untuk data nonseismik yaitu gravity dan CSAMT (controlled source audio-frequency magnetotelluric). Penggunaan standar ini berguna untuk kebutuhan manajemen data untuk pengambilan keputusan. Untuk data seismik 2D menghasilkan dua Data Model Seismik PPDM 3.9 yaitu Seismic Acquisition dan Seismic Spatial. Dari Data Model tersebut menghasilkan empat tabel diantaranya SEIS_SET, SEIS_ACQTN_SURVEY,SSEIS_BA_SERVICE, dan SEIS_POINT.

Tabel 1. Penggunaan Data Model Seismik PPDM 3.9

\begin{tabular}{cc}
\hline Data Model & Tabel \\
\hline Seismic Acquisition & SEIS_SET \\
& SEIS_ACQTN_SURVEY \\
& SEIS_BA_SERVICE \\
SEIS_POINT \\
\hline Seismic Spatial & SEIS_SET \\
& SEIS_POINT \\
\hline
\end{tabular}

Data Model Seismik PPDM 3.9 harus dibuat relationship class yang beracuan dari desain ERD (Entity Relationship Diagram) sehingga data seismik 2D harus memperhatikan mana yang menjadi primary key-nya.

Tabel 2. Primary Key Data Model Seismik PPDM 3.9

\begin{tabular}{cc}
\hline Tabel & Atribut Primary Key \\
\hline SEIS_SET & SEIS_SET_SUBTYPE \\
& SEIS_SET_ID \\
\hline SEIS_POINT & SEIS_SET_SUBTYPE \\
& SEIS_SET_ID \\
& SEIS_POINT_ID \\
\hline SEIS_ACQTN_SURVEY & SEIS_SET_SUBTYPE \\
& SEIS_ACQTN_SURVEY_ID \\
\hline SEIS_BA_SERVICE & SEIS_SET_SUBTYPE \\
& SEIS_SET_ID \\
& PROVIDED_BY \\
& SERVICE_SEQ_NO \\
\hline
\end{tabular}

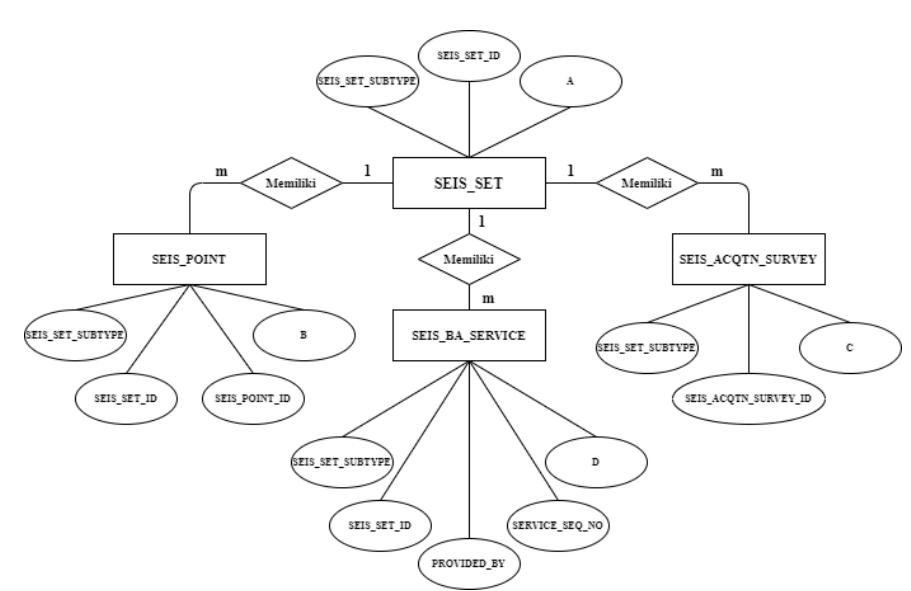

Gambar 4. Desain ERD Untuk Data Seismik 2D 
Untuk hasil kompilasi data nonseismik meliputi data gravity dan CSAMT dapat dilihat pada tabel 3.

Tabel 3. Hasil Kompilasi Data Nonseismik

\begin{tabular}{cc}
\hline Data Nonseismik & Atribut \\
\hline Gravity & Station \\
G_Observation \\
Latitude \\
Longitude \\
X_COORDINATE \\
Y_COORDINATE \\
BA_LONG_NAME \\
BA_TYPE \\
ELEVATION \\
ELEVATION_OUOM \\
AREA_ID \\
AREA_TYPE \\
ACQTN_SURVEY_NAME \\
SEIS_SPECTRUM_TYPE \\
SEIS_DIMENSION \\
START_DATE \\
SHOT_BY \\
ENVIRONMENT \\
SOURCE \\
XE_COORDINATE \\
Y_COORDINATE \\
REMARK \\
BA_LONG_NAME \\
BA_TYPE \\
SEIS_SPECTRUM_TYPE \\
AREA_ID \\
AREA_TYPE DIMENSION \\
SHOT_BY \\
ENVIRONMENT \\
SOURCE \\
\hline CSAMT \\
\hline
\end{tabular}

\section{Publish Service ke Dalam Cloud Geospasial}

Untuk melakukan publish service ke dalam cloud geospasial self-managed services (ArcGIS Enterprise PT Pertamina Hulu Energi) perlu mengetahui terlebih dahulu prosedur alur terkait data di dalam arsitektur sistem tersebut.

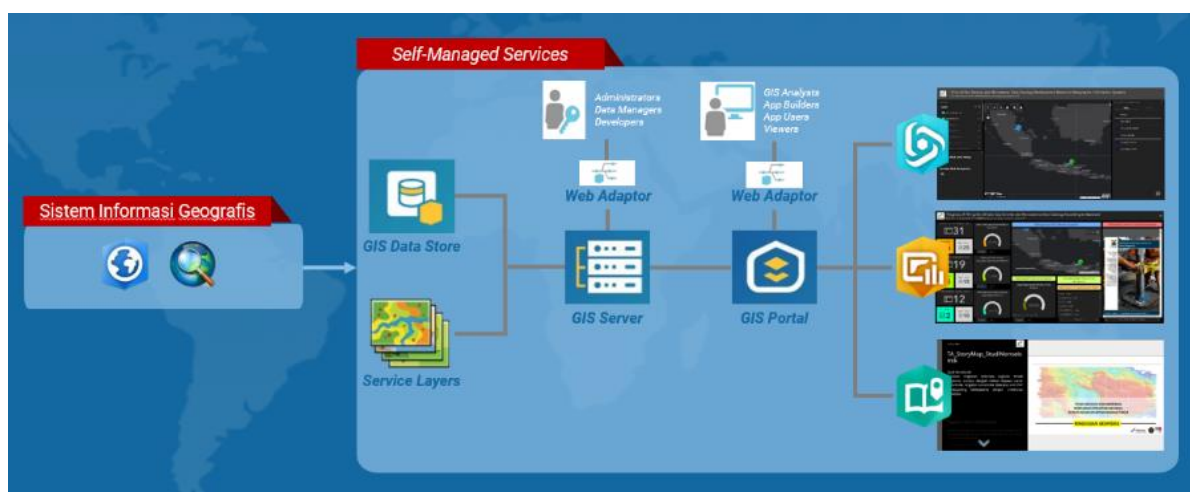

Gambar 5. Arsitektur cloud geospasial self-managed services 
Dalam arsitektur tersebut terdapat beberapa komponen yaitu perangkat lunak sistem informasi geografis, service layers, GIS data store, GIS server (ArcGIS Server), GIS portal (Portal for ArcGIS), dan web adaptor. Komponen GIS data store, GIS server, dan GIS portal tidak dikelola provider perangkat lunak (third-party management) atau dikelola sendiri oleh PT Pertamina Hulu Energi sehingga user tidak dibatasi oleh credit penggunaan. Perangkat lunak sistem informasi geografis digunakan untuk merancang data spreadsheet menjadi katalog berupa tabel, data spasial, dan relationship class. Katalog data tersebut tersimpan di dalam enterprise geodatabase agar nantinya bisa dilakukan publish. Jika diperlukan penambahan data baru maupun editing oleh multi-user berupa data spasial atau nonspasial, data di dalam enterprise geodatabase harus dilakukan register as versioned.

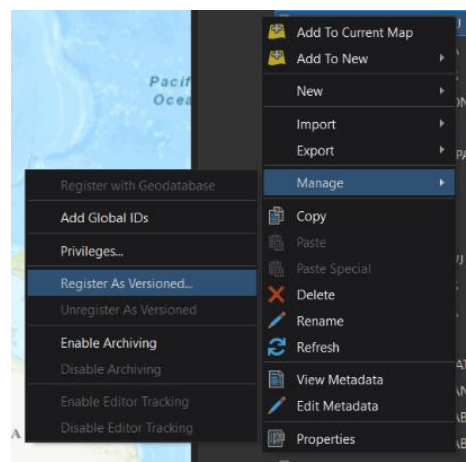

Gambar 6. Register Data as Versioned pada Enterprise Geodatabase

Data yang sudah diolah di dalam perangkat lunak sistem informasi geografis disimpan dalam format *.mxd kemudian akan menjadi service layers. GIS data store dan service layers yang sudah terpublish akan masuk ke dalam GIS server menggunakan ArcGIS Server. GIS server merupakan back-end sistem komputer yang menyediakan jenis layanan (service) sistem informasi geografis di PT Pertamina Hulu Energi secara opsional siapa pun yang memiliki koneksi intranet atau koneksi internet dengan menggunakan VPN (Virtual Private Network). Setelah itu data tersebut akan tersedia dan dapat diakses melalui GIS portal menggunakan Portal for ArcGIS. Untuk penambahan data baru agar tersedia di GIS portal hanya bisa dilakukan oleh anggota PT Pertamina Hulu Energi yang terdaftar pada cloud geospasial self-managed services. Berikut adalah karakteristik kewenangan anggota pada cloud geospasial self-managed services.

Tabel 4. Karakteristik Kewenangan dalam GIS Portal

\begin{tabular}{cccc}
\hline Kewenangan & User & Publisher & Administrator \\
\hline Mencari dan menggunakan service items yang bersifat publik & $\sqrt{ }$ & $\sqrt{ }$ & $\sqrt{ }$ \\
Mencari dan menggunakan service items yang bersifat pribadi & $\sqrt{ }$ & $\sqrt{ }$ & $\sqrt{ }$ \\
Membuat dan membagikan services item pada portal & $\sqrt{ }$ & $\sqrt{ }$ & $\sqrt{ }$ \\
Publish konten baru (feature/image services) & $\times$ & $\sqrt{ }$ & $\sqrt{ }$ \\
Mengurus ArcGIS suatu organisasi & $\times$ & $\times$ & $\sqrt{ }$ \\
Mengelola pengguna dan hak istimewa pengguna & $\times$ & $\times$ & $\sqrt{ }$ \\
Mengelola service items yang dibuat oleh pengguna lain & $\times$ & $\times$ & $\sqrt{ }$ \\
Menggunakan aplikasi web pada ArcGIS & $\sqrt{ }$ & $\sqrt{ }$ & $\sqrt{ }$ \\
\hline
\end{tabular}

\section{Overview Feature Service dan Image Service}

Feature service (data vektor) dan image service (data raster) yang sudah terpublish disimpan dalam bentuk web map. Web map digunakan untuk penarikan layer pada proses layouting di aplikasi berbasis sistem informasi geografis pada ArcGIS Enterprise PT Pertamina Hulu Energi. Dalam tampilan halaman overview feature service dan image service terdapat judul service, tanggal service dipublish atau diupdate, deskripsi yang menjelaskan tentang isi dari feature service, dan layer apa saja yang ditampilkan. 


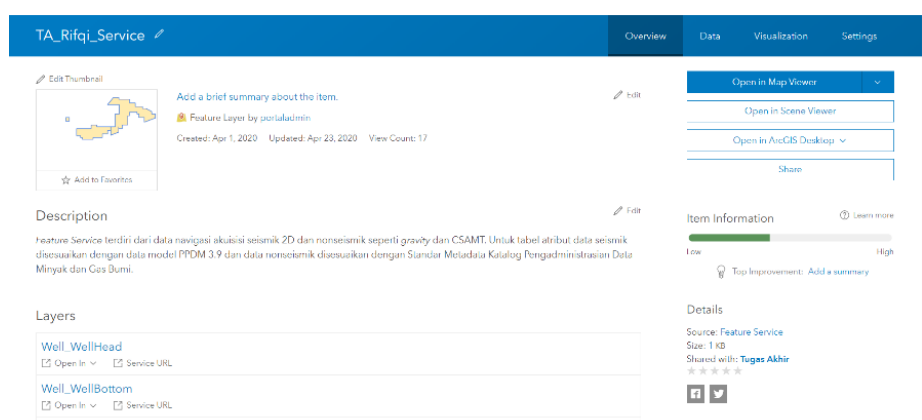

Gambar 7. Overview Feature Service Data Seismik dan Nonseismik

Untuk feature service terdapat tabel atribut di dalamnya karena service yang dipublish berupa data vektor. Pengguna pada self-managed services (ArcGIS Enterprise PT Pertamina Hulu Energi) yang memiliki akses dapat melihat hasil data spreadsheet dalam bentuk tabel dan dapat dilakukan perubahan (editing) data.

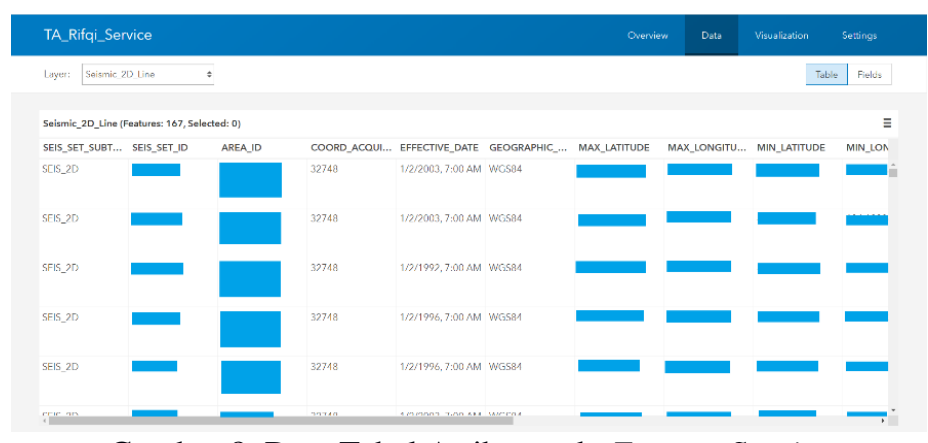

Gambar 8. Data Tabel Atribut pada Feature Service

\section{Pengolahan Web Map}

Web map yang sudah tersedia di dalam GIS portal harus dilakukan pengaturan kembali seperti tampilan pop up, label yang ingin ditampilkan, image display, dan menambahkan attachment. Fitur pop up berfungsi untuk menampilkan informasi atribut pada objek di feature service yang ditunjuk oleh pointer kursor pada layar komputer.

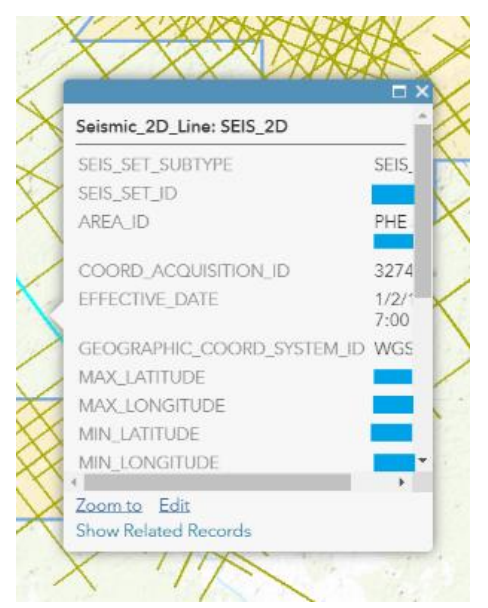

Gambar 9. Tampilan Pop Up pada Feature Service 
Label adalah potongan teks pendek yang mendeskripsikan feature service dalam sebuah layer dan membantu pengguna memahami feature service yang terlihat. Pengaturan untuk menampilkan label pada feature service meliputi teks atribut yang ditampilkan, besar huruf, pengaturan teks, warna teks, perataan teks, dan skala zooming teks.

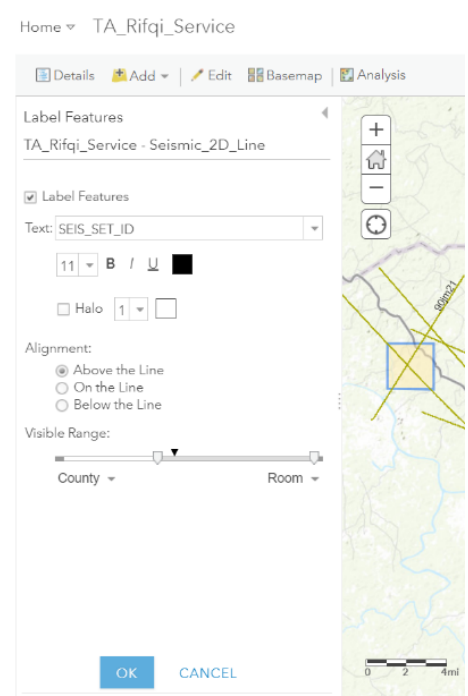

Gambar 10. Pengaturan Untuk Menampilkan Label pada Feature Service

Pengaturan image display pada feature service di web map meliputi warna simbol, tingkat transparan simbol, lebar garis, jenis simbol.

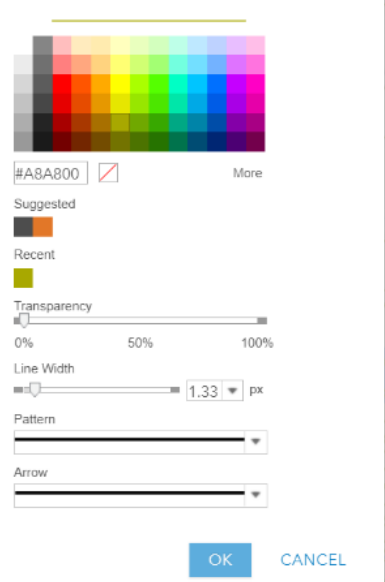

Gambar 11. Pengaturan Untuk Image Display pada Feature Service

Menambahkan attachment dilakukan untuk melengkapi informasi katalog data seismik dan nonseismik berupa gambar penunjang terhadap feature service yang ada. Gambar penunjang bisa penampang seismik 2D dan penampang gravity dengan CSAMT. 


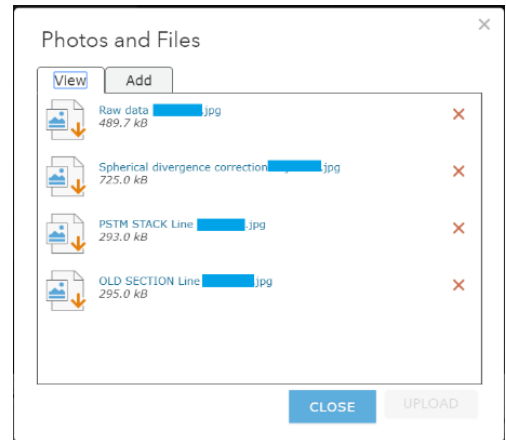

Gambar 12. Menambahkan Attachment pada Feature Service

\section{Web App Katalog Data Seismik dan Nonseismik}

Aplikasi web app merupakan aplikasi hasil pengembangan katalog data seismik dan nonseismik berbasis sistem informasi geografis yang dikustomisasi dalam bentuk web. Web app pada self-managed services bersifat siap pakai. Proses layouting pada aplikasi ini menampilkan web map layer, legenda peta, kolom query, dan widget untuk membantu pencarian dan analisis data dalam pengambilan keputusan.

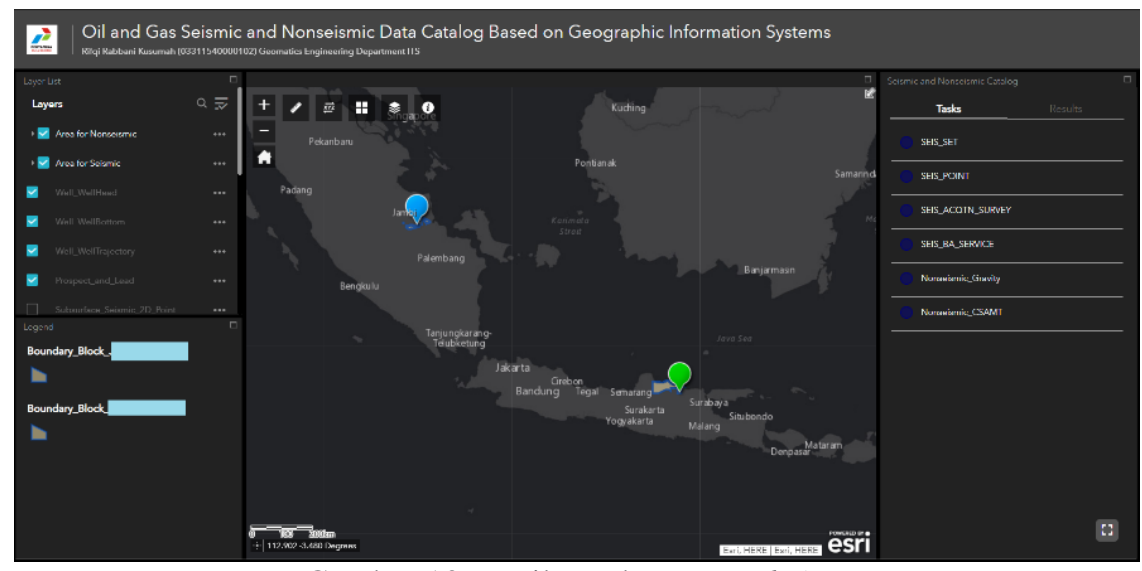

Gambar 13. Hasil Pembuatan Web App

Fungsi utama pembuatan web app adalah untuk menampilkan data tabel atau atribut yang sudah masuk ke basis data melalui enterprise geodatabase menggunakan fungsi query. Fungsi query memiliki kemampuan untuk memanggil banyak data seismik dan nonseismik beserta melihat relationship class antar data.
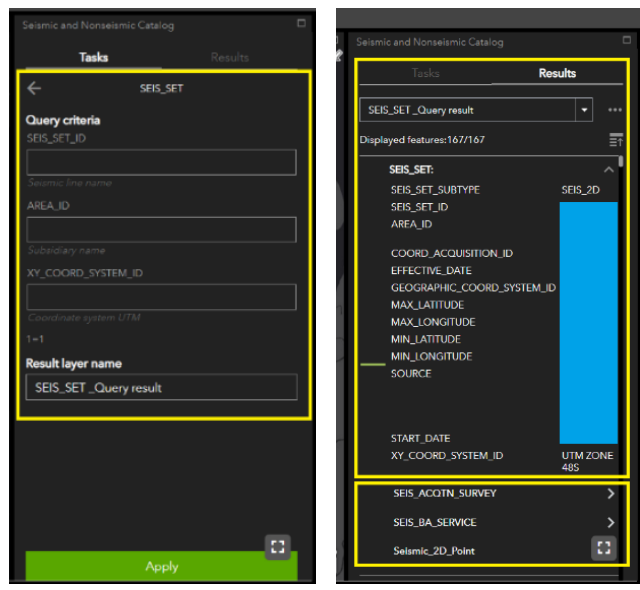

Gambar 14. Tampilan Kolom Query Data SEIS_SET (Kanan) dan Hasil Pencarian Data SEIS_SET Beserta Relationship Class (Kiri) 
Widget yang dibuat pada web app meliputi navigasi zooming, ruler, coordinate conversion, basemap, dan about.

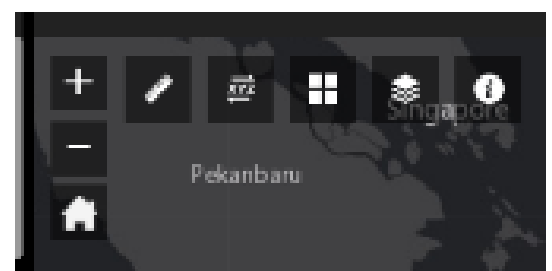

Gambar 15. Tampilan Widget pada Web App

\section{Operations Dashboard}

Aplikasi operations dashboard merupakan aplikasi hasil pengembangan katalog data seismik dan nonseismik dengan interface yang menampilkan infografik progress pengisian katalog data seismik dan nonseismik. Infografik yang ditampilkan dalam bentuk presentase sudah sesuai dengan hasil kompilasi data

seismik dan nonseismik yang sudah terstandarisasi. Pada operations dashboard juga menampilkan lampiran dokumen standarisasi.

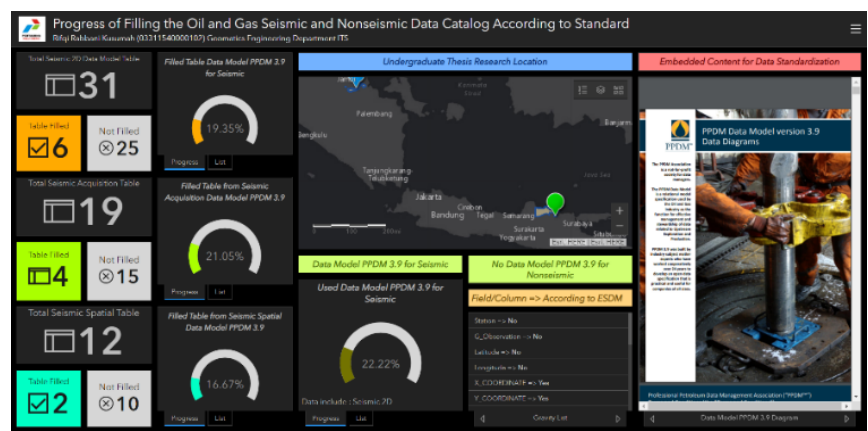

Gambar 16. Hasil Pembuatan Operations Dashboard

\section{Story Maps Studi Nonseismik}

Aplikasi story maps merupakan aplikasi dengan template yang digunakan yaitu story map journal pada cloud geospasial self-managed services (ArcGIS Enterprise PT Pertamina Hulu Energi) yang berfungsi untuk memberikan narasi singkat terkait peta dan media data nonseismik. Di dalam story maps menjelaskan kegiatan yang sudah dilakukan terhadap studi nonseismik seperti uraian pekerjaan pada akuisisi data gravity maupun akuisisi data CSAMT (controlled source audio-requency magnetotelluric) dan service apa saja yang bisa divisualisasikan ke dalam sistem informasi geografis untuk menunjang manajemen data.
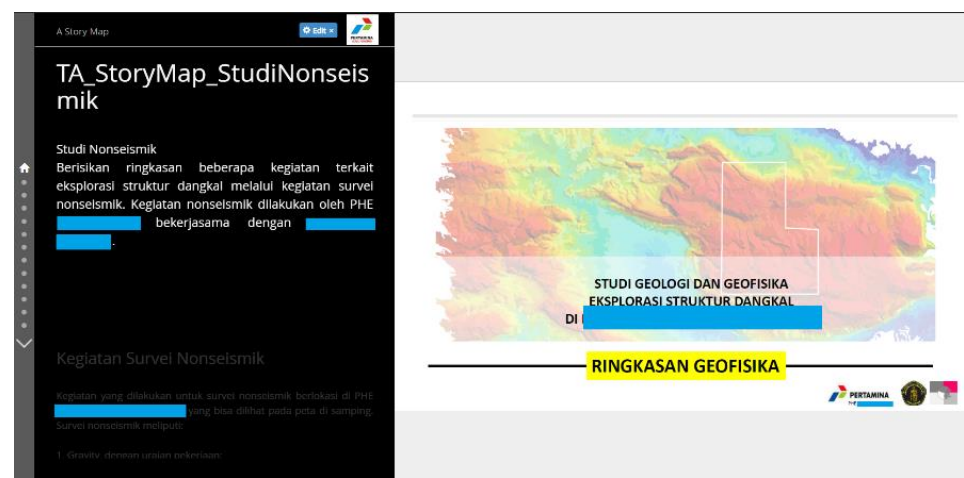

Gambar 17. Hasil Pembuatan Story Maps 


\section{Kesimpulan}

Kesimpulan pada penelitian ini yaitu data spreadsheet seismik dan nonseismik yang sudah dikompilasi berhasil dikonversi ke dalam perangkat lunak sistem informasi geografis berupa katalog data yang berisi tabel, data spasial, dan relationship class. Katalog data tersimpan di dalam enterprise geodatabase yang nantinya bisa dilakukan publish ke dalam cloud geospasial self-managed services sehingga data bersifat online. Penggunaan cloud geospasial self-managed services menghasilkan web map yang berisikan feature service (data vektor) dan image service (data raster) yang terpublish di dalam GIS portal. Kemudian web map dikembangkan menjadi tiga aplikasi yaitu web app, operations dashboard, dan story maps. Fungsi utama web app adalah untuk pemanggilan data menggunakan query beserta melihat relationship class antar data, lalu operations dashboard untuk menampilkan infografik progress pengisian katalog data seismik dan nonseismik, dan story maps untuk melihat ringkasan singkat terkait studi nonseismik. Kelebihan cloud geospasial selfmanaged services memiliki tingkat keamanan yang tinggi karena hanya bisa diakses pengguna PT Pertamina Hulu Energi. Selain itu, user tidak dibatasi oleh beban credit penggunaan karena semua komponen dikelola sendiri. Kelebihan yang terakhir yaitu sebagai sistem integrasi data yang dapat terus digunakan di masa yang akan datang baik untuk membantu tim manajemen data dalam melakukan pengambilan keputusan, analisis, maupun pelaporan secara efektif.

\section{Ucapan Terimakasih}

Penulis mengucapkan terima kasih kepada pihak PT Pertamina Hulu Energi yang telah memberi kesempatan penulis untuk melakukan penelitian ini.

\section{Daftar Pustaka}

Anam, S. (2012). Peranan Geodesi Geomatika dalam Industri Migas dan Permasalahannya. Jakarta: MDGTI PT Pertamina EP.

Charter, D. (2004). Desain dan Aplikasi GIS. Jakarta: PT Elex Media Komputindo.

ESRI. (2017). Portal for ArcGIS. <URL:http://server.arcgis.com/en/portal/>. Dikunjungi pada tanggal 13 September 2019, pukul 13.00 WIB.

IOGP. (2019). Geomatics Support During the Upstream Oil and Gas Life Cycle. <URL:https://32zn56499nov99m251h4e9t8-wpengine.netdna-ssl.com/wp

content/uploads/2020/06/Geomatics_EGM2019_Posters.pdf>. Dikunjungi pada tanggal 12 Desember 2019, pukul 10.15 WIB.

Sheriff, R. (1991). Encyclopedic Dictionary of Exploration Geophysics. Tulsa: Society of Exploration Geophysicists.

EY SA This article is licensed under a Creative Commons Attribution-ShareAlike 4.0 International License. 